\title{
Hydrological flow metrics for ecological impact assessment of river basins in Northern Australia
}

\author{
$\underline{\text { Caleb C. Amos }}^{\text {a,b }}$, Fazlul Karim ${ }^{\text {b, Danial Stratford }}{ }^{\text {b }}$ \\ ${ }^{a}$ School of Computing, Engineering and Mathematics, Western Sydney University, Australia \\ ${ }^{b}$ CSIRO Land and Water, Canberra, ACT 2601, Australia. \\ E-mail: C.Amos@westernsydney.edu.au
}

\begin{abstract}
Understanding the nature of flow regimes is important for the management of engineering, environmental and ecological assets in a river-floodplain system. This study presents results from an analysis on nine hydrological flow metrics that are considered important for ecological impact assessment. The study includes river basins across three regions of northern Australia (the Fitzroy River in Western Australia, the Finniss, Adelaide, Mary and Wildman rivers in the Northern Territory and the Mitchell River in Queensland). The goal of this research is to provide a rapid characterisation of flow variability occurring throughout the regions and a baseline understanding of river flows to inform ongoing river modelling and ecological impact assessment studies. The analyses include an assessment of the availability and quality of observed streamflow data for the northern Australian rivers and quantification of nine flow metrics representing variability in high, low and long-term flows. Observed daily streamflow data for northern Australian regions were downloaded from WA's Department of Water (27 stations for the Fitzroy), NT's Government Water Data Portal (30 stations for Darwin Catchments), and QLD's Water-Monitoring Information Portal (30 stations for the Mitchell). Flow data were also obtained for Cooper Creek (arid), Belyando River (dry tropical) and Tully River (wet tropical) for comparison. Data quality for each stream gauge was checked using R-Script and categorised as good, fair, poor, unverified, non-conforming or missing. Flow Duration Curves (FDCs) and nine ecologically significant flow metrics, hereafter referred to Hydrological Response Variables (HRVs) were investigated. HRVs were compared within and between the catchments to flow characterises of individual catchment were evaluated. FDCs were calculated in two ways, firstly for the whole data series together and secondly for each year to produce a visual understanding of inter annual variability. To further characterise the river flow nine HRVs were extracted representing flow variability in low and high flow conditions. These include the (i) first percentile (P01), (ii) number of zero flow days per year (ZFD), (iii) number of low flow days per year (LFD), (iv) number of low flow spell (LFS) and (v) length of the longest low flow spell (LLFS) representing low flow condition, (vi) $99^{\text {th }}$ percentile flow (P99) and (vii) number of high flow days (HFD) representing high flow condition, and (viii) annual flow volume (AF) and (ix) inter-quartile range in daily flow (IQR) representing flow volume and variability.
\end{abstract}

Results show both high and low flow regimes are highly variable within and between river basins across the northern region which appears to be part of the current natural flow regime. High variability means that streamflow persists some years and not others and implies that slight changes in water extraction may affect this balance. The Fitzroy has a higher degree of streamflow of variability than the Mitchell. Comparison with other catchments shows, that the Tully River (wet tropical) has the most reliable flow while Cooper Creek (arid) and Belyando River (dry tropical) are less reliable. The HRVs, being a yearly plot, affords a graphical representation of the number of years of data, while showing the inter-annual variability. The Fitzroy River (at Fitzroy Crossing) has the maximum number of no flow days, while the Mitchell has few no flow days. There is scope for more detailed comparisons to be made both within and between the catchments and to gap fill some of the data used due to the missing and unverified data that it contains. Data could also be correlated with the available rainfall data and historic records. Regular updates with new data as it becomes available will increase the data quantity and quality. This information will be useful to ecological assessment on future agricultural and/or infrastructure developments projects in north regions Australia.

Keywords: Streamflow, ecology, hydrological response variable, Fitzroy, Mitchell, Darwin 


\section{INTRODUCTION}

The northern Australia, unlike the more developed south, is generally a poorly studied region of Australia with a unique climate and geomorphology. Its highly variable hydrology (seasonally, annually and perhaps inter decadal and longer term) forms the foundation of many ecological processes. The ecologic and natural value, the cultural value, and the agricultural potential of these regions make them highly significant regions. In the push to develop the north it is important to study these regions to avoid negative environmental impact as has occurred in the past. Understanding the nature of flow regimes is important for the management of environmental and ecological assets, engineered structures, and agricultural water use in a river-floodplain system. Three regions across the north have been chosen for comparison, namely the Fitzroy River in Western Australia, the Finniss, Adelaide, Mary and Wildman rivers in the Northern Territory and the Mitchell River in Queensland. These areas include important floodplain wetlands which are among the most threatened habitats on earth (Bunn et al., 2002). Understanding how changes may happen across the floodplains is important for identifying and managing critically threatened floodplain ecosystems (Karim et al., 2016). In this region historical streamflow data represents a shorter historic record than rainfall; however there is over 60 years of streamflow data available at some gauges for analysis.

The goal of this research is to use hydrologic modelling methods to provide a rapid characterisation of flow variability throughout the regions and a baseline understanding of river flows to inform ongoing river modelling and ecological impact assessment studies. This is also being used as a first step towards a more complex hydrodynamic model that that can produce a much greater variety of results such as Flood plain inundation, flood duration, area of flood, depth of flood, velocity of water flow (Karim et al., 2011). The analyses include an assessment of the availability and quality of observed streamflow data and quantification of key hydrological flow metrics (representing variability in high, low and long term flows) that are likely important for understanding potential ecological impact. Differences in the flow regime between the selected river basins are highlighted by presenting plots of intra and inter catchment gauges together. All three selected regions are then compared with key gauges from other Australian catchments with different climatic conditions, namely arid, wet tropical, and dry topical regions.

\section{STUDY SITES}

All Three study sites (Figure 1) are typical of the far north being highly seasonable with over $90 \%$ of rainfall and runoff occurring between Nov and Apr/May and potential evaporation exceeding rainfall up to 4 times (CENRM, 2010; CSIRO, 2009). Compared with other continents, wet-dry tropical savannah systems in northern Australia have a comparatively short summer wet season with high intensity rainfall (Ward et al., 2013). There is however still some variability between the regions as the streamflow data reflects.

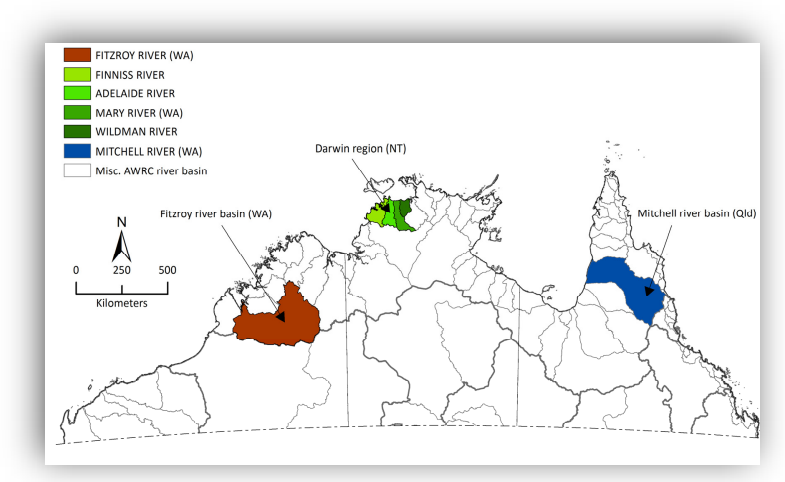

Figure 1. Study sites (Stone, 2016)

The Fitzroy flows 733 kilometres from the King Leopold

and Mueller Ranges into King Sound south of Derby and is one of Australia's the largest unregulated catchments with an area of $94,000 \mathrm{~km}^{2}$ (Department of Water, 2009). The Gauge at the Fitzroy Crossing monitors $46,133 \mathrm{~km}^{2}$ and is comparable in catchment size to the most downstream gauge in the Mitchell, that at Dundbar, $45,872 \mathrm{~km}^{2}$. This gauge has the longest streamflow record in the Fitzroy with over 60.2 years of data. Seasonally the river change from $15 \mathrm{~km}$ wide in the wet season to not much more than a series of disconnected waterholes in the dry (CENRM, 2010; Petheram et al., 2014). Flooding leads to a boom in productivity sustaining up to 90 wetlands in its mid to lower reaches (Karim et al., 2016), while the groundwater baseflow helps to maintain some permanent pools as important refuge habitat (Vogwill 2015). The Fitzroy is home to Geikie Gorge, the Camballin swamps, and Le Lievre swamp which are of great ecological significance and listed in the directory of important wetlands (Environment Australia, 2001; SKM, 2009).

The Darwin catchments studied here are the Finniss, Adelaide, Mary and Wildman river basins with combine area of $30,000 \mathrm{~km}^{2}$. The largest catchment area monitored is the Adelaide River - Dirty Lagoon open station at $4,325 \mathrm{~km}^{2}$. The river flows reflect this with large wet-season flows and small dry-season flows resulting in 
extensive seasonal wetlands and floodplain systems. The region's ecology is suited to this highly variable hydrological pattern. The catchments are home to a number of national parks with five wetlands being of national significance. Along the Finniss River these are the Finniss Floodplain and Fog Bay Systems, and the Port of Darwin; along the Adelaide and Mary Rivers there are the Adelaide River Floodplain System, and the Mary Floodplain System; and along the Wildman section: Kakadu National Park (Environment Australia, 2001).

The Mitchell catchment is approximately 71,000 $\mathrm{km}^{2}$ (Rustomji, 2010) flowing for $750 \mathrm{~km}$ from the top of the great dividing range only $50 \mathrm{~km}$ inland of Cairns all the way across the Cape York Peninsula Basin's into fluvial megafan, housing extensive Lacustrine (lake) systems, and finally into the Gulf. The Mitchell has Queensland's largest discharge at $11300 \mathrm{GL} /$ year. The most downstream gauge (Mitchell at Koolatah, now moved to Dunbar) monitors $45,872 \mathrm{~km}^{2}(65 \%)$ of this catchment. The Walsh River gauge at Nullinga has the longest streamflow record in the Mitchell Catchment with 60 years of data. Floods in the Mitchell are now known to be "flashy" with inundation lasting between 8 and 10 weeks (Ward et al., 2013). River flows have high inter-annual variability with many years having above or below average runoff (CSIRO, 2009). The region's ecology is suited to this highly variable hydrological pattern (CSIRO, 2009). There are national parks within the catchment with three wetlands of national significance: the Mitchell River Fan Aggregation, the Southeast Karumba Plain Aggregation and the Spring Tower Complex which contains rare (in Australia) karst wetland (Department of the Environment, 2010; Environment Australia, 2001). Ecological water features include permanent waterholes and floodplains that are habitat to a wide range of waterbirds (Department of the Environment, 2010), tidal flats, stream channels, ephemeral and permanent wetlands as well as estuarine and coastal marine waters. Many species are dependent on river flow (Bayliss et al., 2014). Upper catchment riverine systems have overhanging vegetation but this reduces to the fringe in most of the Lacustrine and Palustrine (Ward et al., 2013).

\section{METHODS}

\subsection{Data preparation and analysis}

Observed flow data for Fitzroy (27 stations), Darwin (16 open stations, 14 closed) and Mitchell (12 open stations, 18 closed) catchments were downloaded from WA's Department of Water, NT's Government Water Data Portal, and QLD's Water-Monitoring Information Portal in the form of daily streamflow data. For comparison with other regions flow data were obtained for Cooper Creek (arid), Belyando River (dry tropical) and Tully River (wet tropical). Some stations had no, or limited flow data and so were excluded, and generally open stations were preferred. In one case in particular the station was closed and moved about $1 \mathrm{~km}$ downstream, the data from both these stations were checked and merged.

Daily streamflow data in the form of csv files were analysed using R-Script. Graphical outputs were also used using R-Script with some supplementing with Excel. This allowed for rapid assessment of the data quality and quantity. The data quality for each stream gauge was checked and then analysed to produce Flow Duration Curves and Hydrological Response Variables. Inter and Intra catchment basis and finally key gauges were compared with selected gauges from Australian arid, wet and dry tropical climates. For the inter catchment comparisons the gauges from each catchment were categorised according to the size of the sub catchment they measure $\left(<700,700-3999,4000-14999,15000-25000,>25,000 \mathrm{~m}^{2}\right)$. Darwin catchments were not large enough to be included in the upper two categories.

\subsection{Streamflow data quality}

The length and quality of data was assessed using R- Script and summarised in Excel. Figure 2 shows the data quality for the Mitchell stations. Quality codes were categorised according to a joint publication between CSIRO and the Bureau of Meteorology (Zhang et al., 2013). The publication summarises the different quality codes that each state as good, fair, poor, unverified, nonconforming or missing.

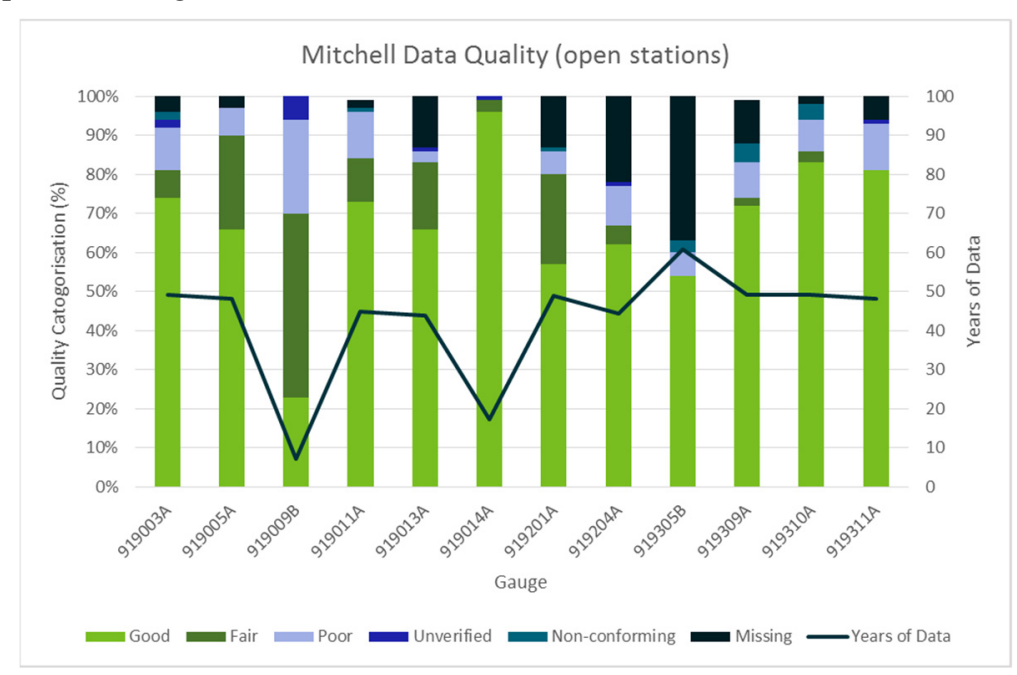

Figure 2. Data quality summary for Mitchell station 


\subsection{Flow duration curves}

A flow duration curve (FDC) presents flow/discharge $\left(\mathrm{Q} \mathrm{m}^{3} / \mathrm{s}\right)$ plotted against exceedance probability (also called fraction of time flow exceeded a certain threshold). Flow is generally plotted on a $\log _{10}$ scale, but was also plotted on a linear scale for comparison. These are calculated by using scripts built in $\mathrm{R}$ to organise the data into descending order from Qmax to Qmin (often zero) and then calculating the \% of data that exceeds each value. These were calculated in two ways, firstly for the whole data series together and secondly for each year to give a visual understanding of inter annual variability.

\subsection{Ecologically significant flow metrics}

To characterise the river flow regime ecologically significant flow metrics or hydrologic response variables (HRVs) were calculated. HRVs give statistical data about the flow regime. Nine Hydrological Response Variables (HRVs), represented graphically in Figure 3, were chosen based on Viney (2015). Of these, zero and low flow were of more interest than high flow for ecological assessment. And so Zero flow days, Low flow days, Low Flow spells (days) and Max low flow spell (days) were of interest from the low flow side where as only High flow days were of interest from the high flow side. Annual Flow (GL/year) was also of interest (Viney, 2015; Karim et al., 2016)

These can be subdivided into those that present volume of flow measurements, and those that give daily counts. Noting that, a spell is defined as a period of contiguous days of streamflow for a HRV. Selected nine HRVs are briefly described below:

- $\quad$ AF: the annual streamflow volume (GL/year)

- P1: the daily streamflow rate at the 1 st percentile (ML/day)

- IQR: the inter-quartile range (75th to 25 th percentile) in daily streamflow (ML/day)

- P99: the daily streamflow rate at the 99th percentile (ML/day)

- HFD: days with high flow ( $>90^{\text {th }}$ percentile $)$ per year

- LFD: low streamflow $\left(<10^{\text {th }}\right.$ percentile $)$ days per year

- LFS: low streamflow $\left(<10^{\text {th }}\right.$ percentile $)$ spells per year

- LLFS: the length (days) of the longest low streamflow spell each year (or "Maximum low flow spells" MLFS)

- ZFD: Zero Flow Days

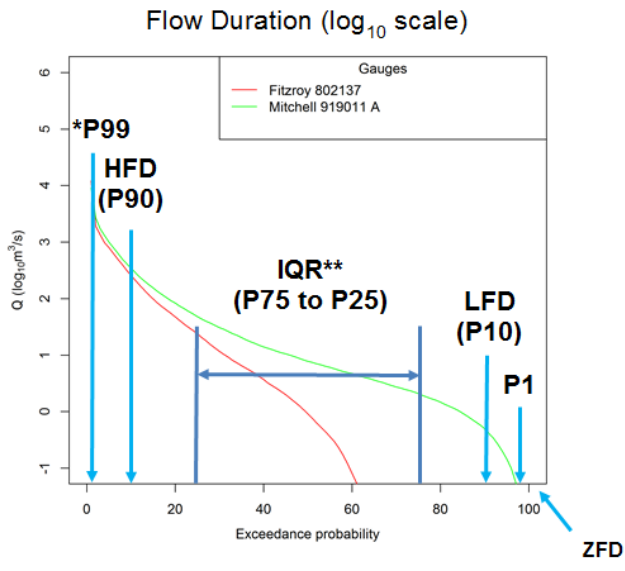

Figure 3. Hydrological response variables (*Percentile **inter-quartile range)

\section{RESULTS}

Results from this analysis can be used as a base to gauge the effect of land use changes and climate variation on ecological assets in the region.

\subsection{Flow regimes across the northern region}

Figure 3 shows FDCs for Fitzroy Crossing (Gauge 802055) and Dunbar in the Mitchell (Gauge 919009), both with similar catchment sizes, as can be seen the Mitchell has a much more reliable flow. Figures 4 \& 5 show the same gauges decomposed into annual flow. 


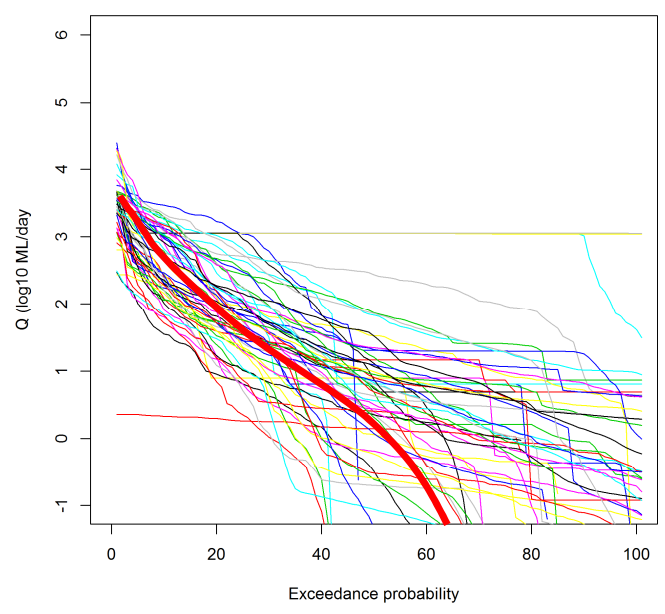

Figure 5. Fitzroy annual flow duration curve

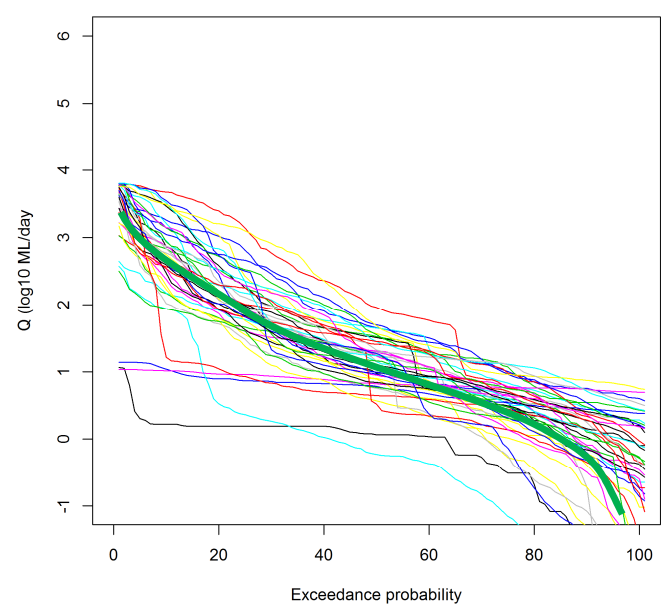

Figure 4. Mitchell annual flow duration curve

This shows that there is high variability with the streamflow persisting some years and not others. Therefore slight changes in water extraction could affect this balance. It also shows that the Fitzroy has a higher degree of variability than the Mitchell at these gauges. Given the data limitation it is reasonable to assume that variability could be more extreme than that seen here. Figure 6 shows a comparison of these two gauges with other catchments. The catchment sizes do not match, but the flow regimes still compare quite well except for the Adelaide River gauge (8170020) which is tidal. Other than that as expected the Tully River (wet tropical) has the most reliable flow. Cooper Creek (arid) and Belyando River (dry tropical) are less reliable.

\subsection{Flow variability}

Hydrologic response variables (HRVs) help read information off the flow duration curves. Some variables are of more interest for particular reasons. Six of the nine variables (Zero flow days, Low flow days, Low Flow spells (days), Max low flow spell (days), High and Annual Flow - AF (GL/year)) were of the most interest from an ecological perspective and so were plotted together. Figure 7 shows the

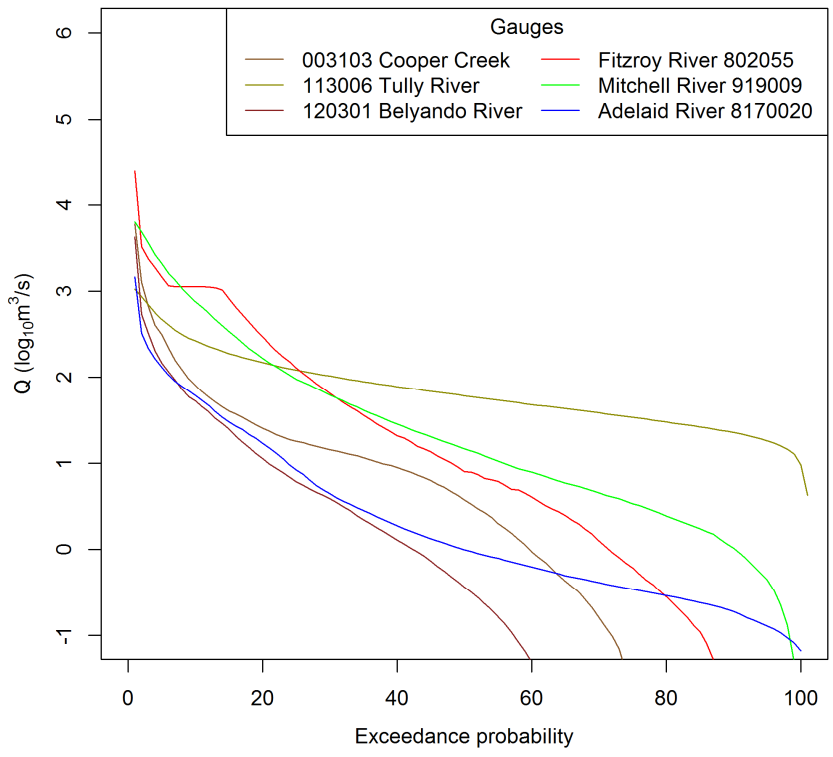

Figure 6. Catchment comparison (flow duration)

Zero flow day plot for the same catchment comparison as Figure 6. Because it is decomposed yearly it gives a graphical representation of the inter-annual variability and also the number of years of data. The Fitzroy (red) has the maximum number of no flow days, while the Mitchell (green) has few no flow days. Belyando River, a dry tropical region (blue) is in-between, with some years greater and some years less no flow days than the Fitzroy gauge.

\section{DISCUSSION AND CONCLUSION}

The unique catchment climates and geomorphology, and limited assessment of the northern Australia leave a large gap in understanding. To minimize negative environmental impacts it is important to increase the knowledge base of the north and to compare this with other regions within

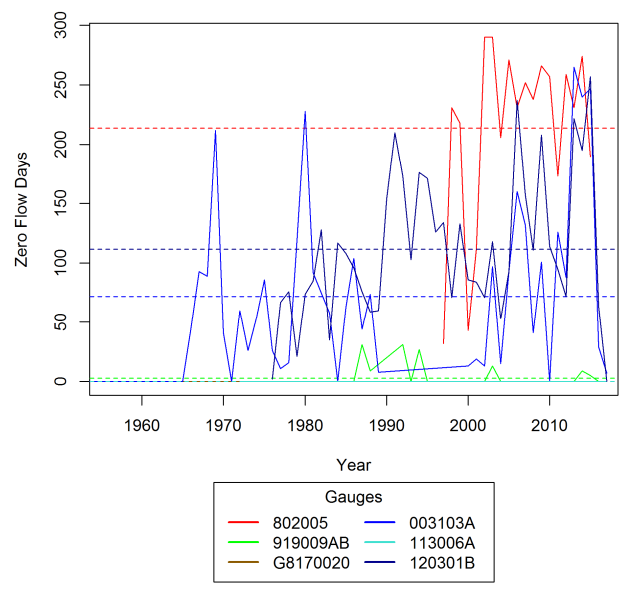

Figure 7. Catchment comparison (zero flow days) 
Australia to appreciate the similarities and differences. Analysis in this report has used all the available streamflow data to date (20-60 years) and found it to have a high degree of variability both seasonally, annually and inter decadal. The Fitzroy shows a higher degree of variability than the Mitchell and Darwin catchments. 50 years of streamflow data represents $50 \%$ of the 100 years of instrumental age (Zillman, 2001) and only $5 \%$ of the last 1000 yrs. The observed data therefore may not be sufficient to show longer term trends, and climatic behaviour outside the observed range might be expected. Some have suggested, using ice core data, that significantly longer and more frequent wet and dry periods were experienced in the preinstrumental compared to the instrumental period (Tozer et al., 2016). The balance of the observed natural flow regime's high variability, with the streamflow persisting some years and not others, could be affected by slight changes in water extraction. Higher natural variation of the flow regime outside that observed could compound this issue, and climate change could compound this further. Comparison of the northern catchments with a wet tropical gauge (Tully River) shows that the flow is comparatively less reliable in the North whereas arid (Cooper Creek) and dry tropical (Belyando River) gauges show an even less reliable flow. There is scope for more detailed comparisons to be made both within and between the catchments and to gap fill some of the data used due to the missing and unverified data that it contains. Data could also be correlated with the available rainfall data and historic records. Regular updates with new data as it becomes available will increase the data quantity by a good percentage, e.g. 5 years represents an $8-25 \%$ increase in most cases. .

\section{ACKNOWLEDGMENTS}

WA Department of Water, NT Government Water Data Portal, and the Department of Natural Resources and Mines (QLD) art to be acknowledged for the supply of the daily streamflow data.

\section{REFERENCES}

Arthington AH, Godfrey PC, Pearson RG, Karim F, Wallace J (2014). Biodiversity values of remnant freshwater floodplain lagoons in agricultural catchments: evidence for fish of the Wet Tropics bioregion, northern Australia. Aquatic conservation: marine and freshwater ecosystems.

Bayliss P, Buckworth R and Dichmont C (2014). Assessing the water needs of fisheries and ecological values in the Gulf of Carpentaria. Final report prepared for the Queensland Department of Natural Resources and Mines. CSIRO, Australia.

Bunn, Stuart E., and Angela H. Arthington (2002). Basic principles and ecological consequences of altered flow regimes for aquatic biodiversity. Environmental management 30.4, 492-507.

CENRM (2010). Fitzroy River catchment management plan. Centre of Excellence in Natural Resource Management, University of Western Australia, Perth.

CSIRO (2009). Water in the Timor Sea Drainage Division. A report to the Australian Government from the CSIRO Northern Australia Sustainable Yields Project. CSIRO Water for a Healthy Country Flagship, Australia

Department of the Environment (2010). Directory of Important Wetlands in Australia. Viewed Viewed December 2015, <http://www.environment.gov.au/node/25064>.

Department of Water (2009). Fitzroy catchment subregion overview and future directions Kimberley regional water plan working discussion paper. Government of Western Australia, Perth.

Environment Australia (2001). A Directory of Important Wetlands in Australia, 3rd edn. Environment Australia, Canberra.

Erskine W, Saynor M, Erskine L, Evans K and Moliere D (2005). A preliminary typology of Australian tropical rivers and implications for fish community ecology. Marine and Freshwater Research 56(3), 253267.

Karim F, Petheram C, Marvanek S, Ticehurst C, Wallace J, Gouweleeuw B. (2011). The use of hydrodynamic modelling and remote sensing to estimate floodplain inundation and flood discharge in a large tropical catchment. 19th International Congress on Modelling and Simulation, Perth, Australia, 12-16 December 2011.

Karim F, Petheram C, Marvanek S, Ticehurst C, Wallace J and Hasan M (2015). Impact of climate change on floodplain inundation and hydrological connectivity between wetlands and rivers in a tropical river catchment. Hydrological Processes. 
Karim F, Viney NR, Wang B, Peeters LJM, Zhang YQ, Marvanek SP, Shi X, Yang A and Buettikofer H (2016). Surface water numerical modelling for the Galilee subregion. Product 2.6.1 for the Galilee subregion from the Lake Eyre Basin Bioregional Assessment. Department of the Environment and Energy, Bureau of Meteorology, CSIRO and Geoscience Australia, Australia.

Petheram C GJ, Wilson P, Stone P, Eades G, Roger L, Read A, Tickell S, Commander P, Moon A, McFarlane D, Marvanek S (2014). Northern rivers and dams: a preliminary assessment of surface water storage potential for northern Australia. CSIRO Land and Water Flagship Technical Report. CSIRO, Australia.

Rustomji P (2010). A statistical analysis of flood hydrology and bankfull discharge for the Mitchell River catchment.

Rustomji P, Shellberg J, Brooks A, Spencer J and Caitcheon G (2010). A catchment sediment and nutrient budget for the Mitchell River, Queensland. Tropical Rivers and Coastal Knowledge (TRACK).

SKM (2009). Ecological assets of northern Australia study. Sinclair Knight Merz, Canberra.

Stone P (2016). Northern Australia Water Resource Assessment Overview - Factsheet. CSIRO Land and Water.

Tozer CR, et al. (2016). An ice core derived 1013-year catchment-scale annual rainfall reconstruction in subtropical eastern Australia. Hydrology and Earth System Sciences 20.5 (1703).

Viney NR (2015). Surface water modelling. Sub methodology M06 from the Bioregional Assessment Technical Programme. Department of the Environment, Bureau of Meteorology, CSIRO and Geoscience Australia, Australia.

Vogwill R (2015). Water resources of the Mardoowarra (Fitzroy River) catchment. University of Western Australia, Perth.

Ward D, Hamilton S, Jardine T, Pettit N, Tews E, Olley J and Bunn S (2013). Assessing the seasonal dynamics of inundation, turbidity, and aquatic vegetation in the Australian wet-dry tropics using optical remote sensing. Ecohydrology 6(2), 312-323.

Zhang Y, Viney N, Frost A, Oke A, Brooks M, Chen Y and Campbell N (2013). Collation of Australian modeller's streamflow dataset for 780 unregulated Australian catchments. Water for a Healthy Country National Research Flagship, 115pp. Catchment Management.

Zillman DJW (2001). A Hundred Years of Science and Service - Australian Meteorology through the Twentieth Century. pp22-50 of the Year Book Australia 2001 by the Australian Bureau of Statistics. 